\title{
Biomimetics Design Optimization and Drag Reduction Analysis for Indonesia N219 Seaplanes Catamaran Float
}

\author{
Allessandro Utomo, Gunawan and Yanuar* \\ Mechanical Engineering, Department of Mechanical Engineering, Universitas Indonesia, \\ Depok 16424, West Java, Indonesia; allessandro.setyo@ui.ac.id (A.U.); gunawan_kapal@eng.ui.ac.id (G.) \\ * Correspondence: yanuar@eng.ui.ac.id; Tel.: +62-813-8578-4345
}

Citation: Utomo, A.; Gunawan; Yanuar. Biomimetics Design Optimization and Drag Reduction Analysis for Indonesia N219 Seaplanes Catamaran Float. Processes 2021, 9, 2024. https://doi.org/ $10.3390 /$ pr9112024

Academic Editors: Luis Puigjaner and Yoshimichi Hagiwara

Received: 12 July 2021

Accepted: 4 November 2021

Published: 12 November 2021

Publisher's Note: MDPI stays neutral with regard to jurisdictional claims in published maps and institutional affiliations.

Copyright: (c) 2021 by the authors. Licensee MDPI, Basel, Switzerland. This article is an open access article distributed under the terms and conditions of the Creative Commons Attribution (CC BY) license (https:// creativecommons.org/licenses/by/ $4.0 /)$.

\begin{abstract}
Design optimization on the Indonesia N219 seaplane catamaran is necessary to provide better service to rural islands of Indonesia. This research aims at decreasing drag using a design based on biomimicry by imitating the hydrodynamic characteristics of sailfish (Istiophorus platypterus) for pontoon floats. The design is then validated using a numerical fluid test using ANSYS Fluent to see the reduction in drag due to the change from a conventional or Wipeline ${ }^{\circledR} 13000$ design to a biomimetics adaptation design. Next, further optimization was carried out based on the adaptation design based on trim tests, clearance tests, and deadrise angle dimensions suitable for biomimicry designs at Froude number speeds of 0.4 to 0.7 . The design results with the adaptation of biomimicry show that a change in the design with this optimization affects a drag reduction that reaches $30 \%$ of the total drag generated by the conventional design.
\end{abstract}

Keywords: design optimization; seaplane; catamaran; biomimicry; drag reduction

\section{Introduction}

Geographically, Indonesia is an archipelagic country with a sea area of up to $77 \%$ of its total area and 17.504 islands, according to the Ministry for Maritime Affairs and Investment of the Republic of Indonesia. These islands consist of four major islands, namely Sumatra, Java, Kalimantan, Sulawesi, Papua, and many other smaller islands. Indonesia relies heavily on inter-regional liaisons for access in and out of these islands as an archipelagic country. However, many areas in Indonesia are challenging to access because waters and various other difficulties separate them. To overcome these problems, the government needs transportation facilities that can reach remote areas, especially those difficult to access by land.

Seaplane has been widely used in sea travel because of its faster travel time than ships and can take off and land both on land and in water. That makes the seaplane superior to ordinary aircraft that require airports to operate. The seaplane was discovered in 1910, but after 1950, there was no further research about the design of a seaplane, especially the float [1]. Seaplane types are divided into two main categories, namely flying boats and floatplanes. The flying boat-type seaplane uses an aircraft fuselage that has been designed into a hull as a landing tool.

In comparison, floatplanes are conventional aircraft that use floats instead of wheels for landing. The fuselage of floatplanes is also always above the waterline. However, it is not uncommon for both types of seaplanes to be equipped with folding landing gear. In addition, the aircraft is included in the amphibian type US Department of Transportation [2]; Seaplane is one of the famous air transportations that can operate in rough terrain. Thanks to its ability to land without the need for a runway, this aircraft can operate in waters such as remote seas and lakes [3].

One design that has succeeded in meeting this need is the N219 aircraft from PT. Dirgantara Indonesia (PTDI). Further development can be done by converting the N219 aircraft into seaplanes to operate above the water surface. The development is in the 
form of a floating pontoon design with a catamaran hull in the fuselage. The design of a catamaran floating pontoon has a total resistance consisting of viscous resistance and wave resistance. Viscous resistance is related to Reynolds number, while wave resistance depends on Froude number [4]. So that reducing this resistance value can be used as an effort to develop catamaran design engineering. However, to reduce the resistance, it is not enough to consider the shape of the hull. Other factors contribute to the resistance value. One of them is the trim value. [5] explained that trim has a significant influence on ship stability and hull durability. Milward has studied the effect of distance between catamaran hulls $[6,7]$, which shows the effect of the clearance configuration on the ship's drag coefficient. Furthermore, the float design is influenced by the deadrise angle between the baseline and the side surface of the floating pontoon that forms a pontoon with a hull of type $\mathrm{V}$ or $\mathrm{U}$ shape. Based on Carry et al. [8], angle change could reduce frictional force, creating a low drag design; therefore, the deadrise angle is another consideration for design manipulation.

So, the concept of optimization using the adaptation design of certain animals, especially aquatic animals [9], is one of the solutions to conventional design changes. However, the natural shape and its effect on drag have been investigated [10]. The finding shows that the sailfish or Istiophorus platypterus can move at a speed of $110 \mathrm{~km} /$ hour. The reduction in frictional resistance in fish reaches 5\% [11] due to its hydrodynamic characteristics. Based on this, this study aims to determine the effect of hydrodynamic adaptation on changes to the design of the Indonesian N219 seaplane float, a configuration of clearance distances, trim analysis, and analysis of changes to the deadrise angle design of the floating pontoon design adaptation of the catamaran sailfish N219 through the manufacture of the numerical test model. The result obtained is a comparison of the results of adaptation of conventional designs optimized based on trim, deadrise angle, and clearance so that the optimum final design is obtained.

\section{Materials and Methods}

The component that will be examined in this research is the float of the N219 aircraft. Float is an additional component on the aircraft in a floating structure that functions as a landing medium on the water surface. This float provides a buoyancy force when on the water surface so that the aircraft can float on it Fenster, 2019 [12]. The float design of the seaplane catamaran requires optimization to obtain a small total water resistance value based on the comparison of its hydrodynamic characteristics in terms of changes in adaptation design, adjustment of trim degrees, deadrise angle, and clearance values. From these parameters, it can be concluded that the optimum design characteristics can be used as a floating pontoon for sailfish adaptation.

The numerical method, often known as Computational Fluid Dynamics (CFD) [13], can solve thousands of simultaneous equations accurately and quickly. In addition, CFD can also produce detailed flow patterns that are impossible to produce by experimental testing. CFD approach [14] has advantages such as being able to perform unlimited quantity and point tests at a time. Other advantages include the existence of a database of CFD investigation results on the previous design to make the following design more manageable.

\subsection{Multiple Design Comparison}

This study uses the CFD method, intending to know whether the hydrodynamic adaptation of the sailfish body to resistance to the initial design of the pontoon float the N219 seaplane catamaran along with the resistance value, drag coefficient $\left(C_{T}\right)$ and flow visualization of its hydrodynamic characteristics ruled by the following equation:

$$
C_{T}=R_{T}\left(0.5 \rho v^{2} S\right)^{-1}
$$

In the equation $R_{T}$ is the frictional drag that occurs on the surface of the float, the velocity of the flow of water is categorized as $\mathrm{v}, S$ is the surface area of the wet float, 
and rho is the density of the water used, namely the density of saltwater $1025 \mathrm{~kg} / \mathrm{m}^{3}$. To achieve this goal, the author examines three designs for which the resistance value, resistance coefficient $\left(C_{T}\right)$ and will be calculated flow visualization of its hydrodynamic characteristics. The following specification of the 3-design tested is shown in Table 1.

Table 1. Design specification of floats.

\begin{tabular}{cccc}
\hline Parameter & WIPLINE $^{\circledR} \mathbf{1 3 0 0 0}$ & $\begin{array}{c}\text { Float Design with } \\
\text { Sailfish Shape }\end{array}$ & $\begin{array}{c}\text { Float Design with } \\
\text { Sailfish Adaptation }\end{array}$ \\
\hline Lwl $(\mathrm{m})$ & 9.88 & 9.29 & 9.29 \\
Height $(\mathrm{m})$ & 1.14 & 1.12 & 1.12 \\
Width $(\mathrm{m})$ & 1.31 & 1.31 & 1.31 \\
Displacement $(\mathrm{kg})$ & 2913 & 2913 & 2913 \\
Draft to baseline $(\mathrm{m})$ & 0.7 & 0.7 & 0.7 \\
\hline
\end{tabular}

Figure 1. designs (a) and (b) will act as controls of this study, where the results of each design will be compared with the test design (c), which is a floating pontoon of results-an adaptation of the body characteristics of sailfish. To achieve the research objectives, namely, to find out the effect of the hydrodynamic adaptation of the sailfish body to resistance on the initial design of the pontoon N219 seaplane buoyancy, three designs researched resistance value, drag coefficient. Furthermore, flow visualization of its hydrodynamic characteristics.

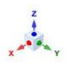
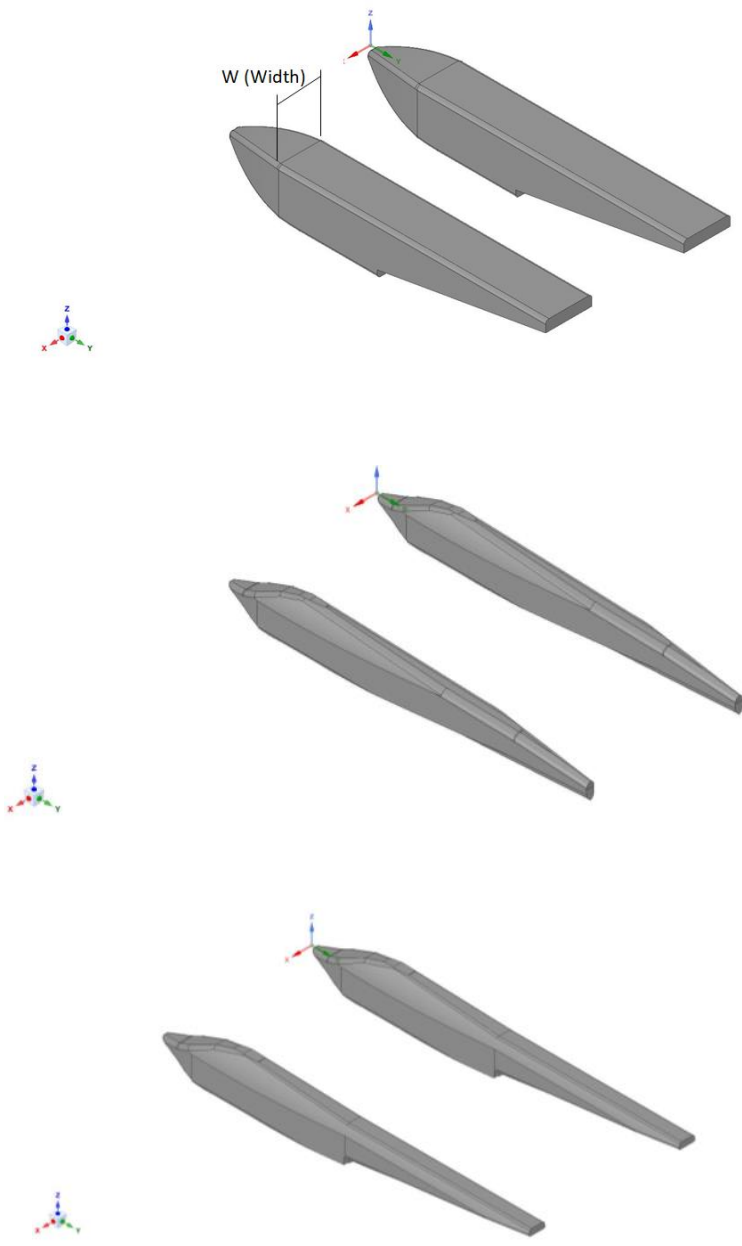

$\underbrace{2}_{x}$ (a)

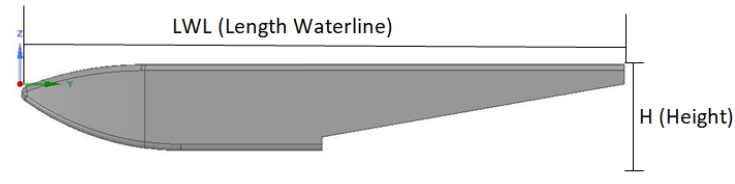

(b)

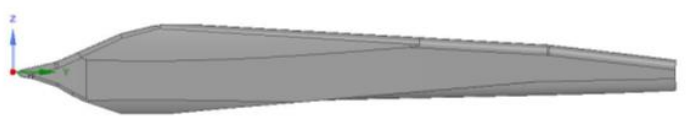

(c)

Figure 1. Design model of amphibian float: (a) Design control I: WIPLINE ${ }^{\circledR} 13000$ commercial floating pontoon designs; (b) Design control II: The catamaran model with the body of a sailfish; (c) Initial design: floating pontoon with sailfish adaptation. 


\subsection{Trim Angle Validation}

Generally, the ship has been optimized to achieve minimum drag after the hull design [15]. Usually in even keel or trim by stern condition for most ships. Trim is the difference between the draft at the stern and the bow of the float. Gudmunsson has discussed the significant effect of trim on ship resistance that has been carried out [3], as discussed in the introduction, with the following equation relationship:

$$
\begin{gathered}
\alpha_{\text {trim }}=\alpha_{1}+0.5\left(\alpha_{2}-\alpha_{1}\right)\left(1+\tanh \left(A C_{v}+B\right)\right) \\
A=5.294\left(C_{v 2}-C_{v 1}\right)^{-1} \\
B=-\left(2.647+A C_{v 1}\right)
\end{gathered}
$$

The equations according to the rules given by [3] $A$ and $B$ are constants calculated in (3) and (4), $\alpha_{1}=$ Trim angle when $C_{v 1}, \alpha_{2}=$ Trim angle when $C_{v 2}$, dan $C_{v}=$ Speed coefficient. Then in Kim et al. [16] and Hajiabadi et al. [17], regarding trim variations on floats, they concluded that determining the vertical slope of the ship has a significant influence on the stability of the ship and the durability of the hull. Meanwhile, according to Sherbaz and Duan [18], the optimization principles of ship trim are based solely on the fact that the ship experiences different drag as it passes through the water for the same speed and draft as changes in its trim. In essence, optimization of float trim recommends selecting trim conditions to achieve minimum resistance.

The discussion [18] concluded that the total resistance value obtained during trim by stern decreased before increasing afterward. This is because each trim change that occurs will change the area and volume of the hull immersed in water and will affect the viscosity and wave resistance. The effect of trim changes is quite significant on the wave resistance, which ultimately affects the total resistance. The lowest total resistance value was achieved at the 0.02-meter value of the stern trim. In this study, the trim value for each float design was carried out to obtain variations in the data when it was simulated. The following is the design of the float with variations of stern trim (Figure 2) and bow trim (Figure 3) with values of $0.44,0.88,1.32,1.76$, and 2.2 degrees.

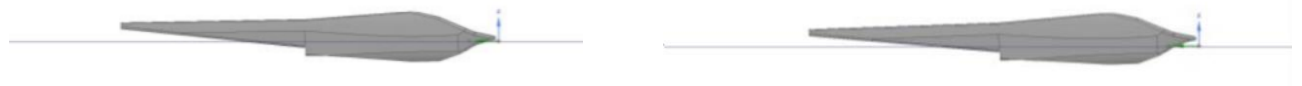

(a)

(b)

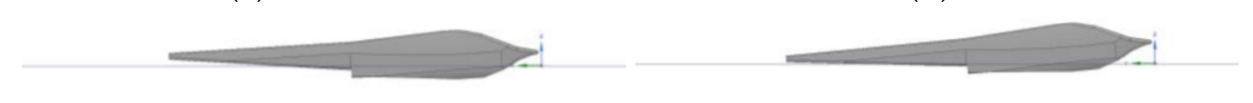

(c)

(d)

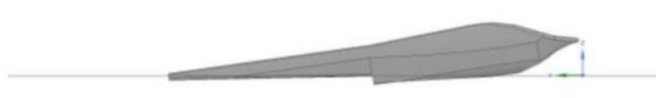

(e)

Figure 2. Initial float with variations of stern trim: (a) 0.44 degree; (b) 0.88 degree; (c) 1.32 degree; (d) 1.76 degree; (e) 2.2 degree. 


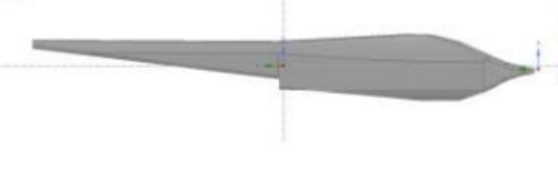

(a)

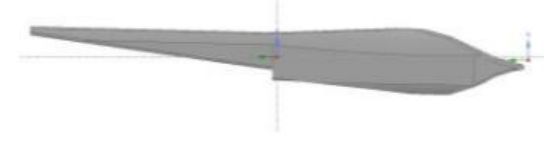

(b)

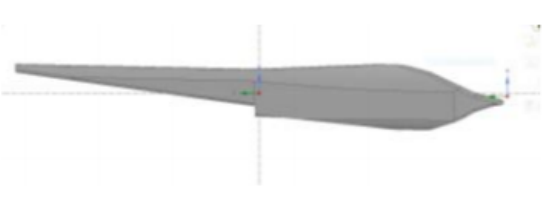

(c)

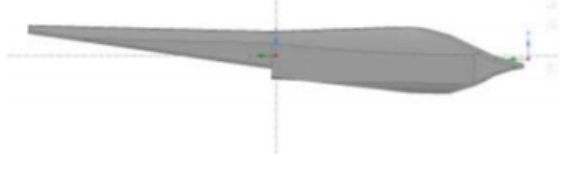

(d)

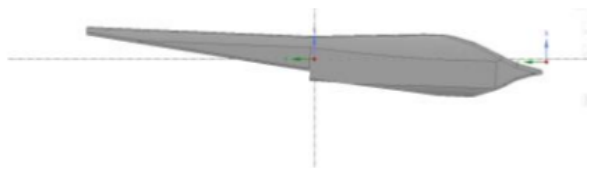

(e)

Figure 3. Initial Float with variations of bow trim: (a) 0.44 degree; (b) 0.88 degree; (c) 1.32 degree; (d) 1.76 degree; and (e) 2.2 degree.

\subsection{Deadrise Angle Validation}

Deadrise angle is an angle between the baseline and the side surface of the floating pontoon that forms a pontoon with the following shape below (Figure 4). The angle starts from 20 degrees to 30 degrees but based on the recommendations given [3,10], the angle over or minus the angle from 20 to 30 is no longer relevant to use or try because the results are no longer efficient. For the use of angles exceeding 30 degrees, it is recommended to use a catamaran hull because it has the same effect but is more stable and efficient [1]. In addition, [1] also provides some findings that the first increase in deadrise in the range of 15 to 30 degrees have little effect on resistance. However, the resistance also increases at a rate that exceeds the float capacity. Furthermore, the bottom balance of the float will increase with increasing deadrise angle but with angle normalization from 20 to 25 degree [19]. Another study [20] also confirmed that the most significant effect of deadrise angle is the dynamic load from the impact on the water surface, decreasing with increasing angle. Therefore, in the study for the second form of validation the research would conduct analysis using 3 different deadrise angle 20, 25, and 30 degrees shown in Figure 4.

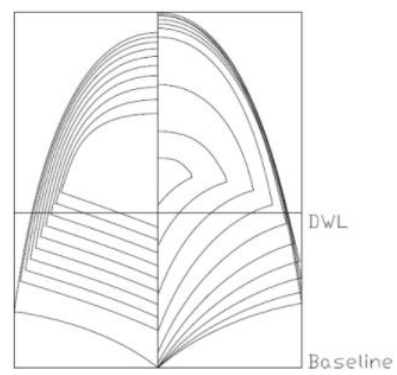

(a)

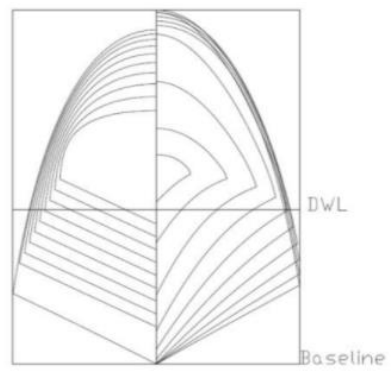

(b)

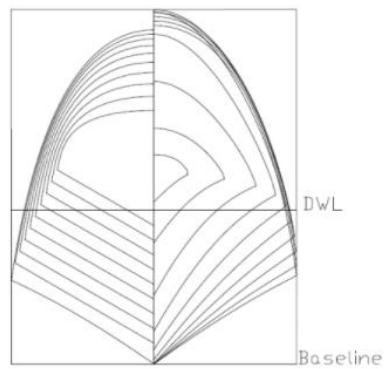

(c)

Figure 4. Initial float with different deadrise angle: (a) Deadrise angle at 20 degrees; (b) Deadrise angle at 25 degrees; and (c) Deadrise angle at 30 degrees. 


\subsection{Clearance Validation}

After the three validations generated above are carried out, the final analysis can now be produced to determine the optimum distance between hulls on the N219 Indonesia Seaplane. Based on the adaptation of sailfish, comparing between floats starts with no biomimicry adaptation to the adaptation form. The last thing that makes floats usable is the shape of the catamaran instead of wheels for anvils on water. Previously, Yanuar et al. [7] has also worked out the effect of clearance on drag reduction where experimental tests are carried out on ponds using the ITTC (International Towing Tank Convention) approach. However, in this study, a numerical test was conducted to see the effect of clearance on wave interference. Wave interference is a phenomenon where waves meet, which results in interaction between the hull (in this case, the float) and water waves to reduce resistance. This effect has been investigated [14] and [21] where the interference factor is better minimized showed in the following equation shown in previous study [7].

$$
\mathrm{IF}=\frac{C_{T}^{(c)}-C_{T}^{(M)}}{C_{T}^{(M)}}
$$

The following equation is IF (Interference Factor), $C_{T}{ }^{(c)}$ represent the total resistance coefficient of two hull, and $C_{T}{ }^{(M)}$ represent the total resistance coefficient of one hull. This effect can be seen where the closer the adjacent floats, the more drag it produced. The clearance between float is represented in Figure 5 by the procedure recommended by other studies [22-24].

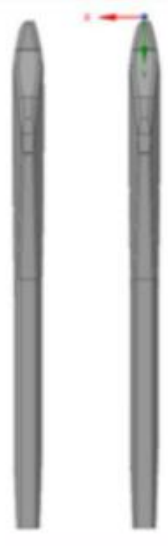

(a)

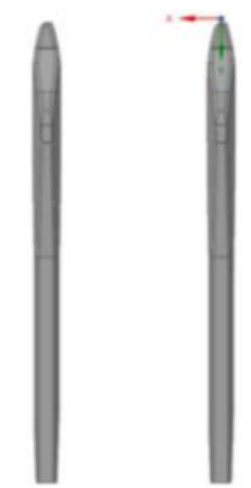

(d)

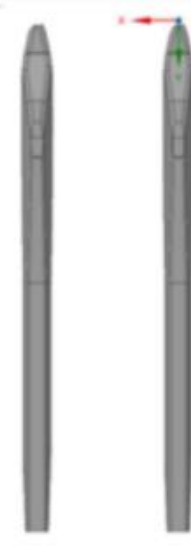

(b)
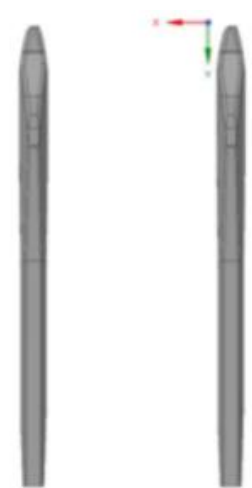

(e)

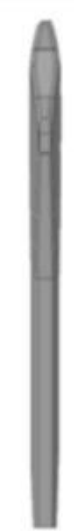

(c)
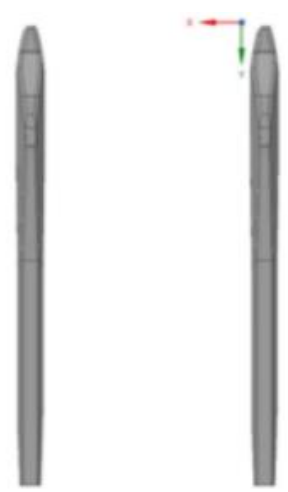

(f)

Figure 5. Initial float clearance configuration: (a) 0.20 ; (b) 0.25 ; (c) 0.30 ; (d) 0.35 ; (e) 0.40 ; and (f) 0.45 . 


\subsection{Computational Fluid Dynamics Setups}

\subsubsection{Pre-Processing}

The pre-processing stage is the first step in carrying out CFD analysis. At this stage, the input problem is carried out following the rules in the software, which consists of the following parts: Forming the geometry of the object and the area surrounding the object as a computational domain; Forming a grid generation that divides the previously defined domain into smaller parts (subdomains); Determine fluid characteristics in the form of density values, fluid temperature, viscosity, and others; Specifies the boundary condition of the geometry object in Table 2.

Table 2. Boundary condition for computational fluid dynamics.

\begin{tabular}{cc}
\hline Parameter & Description \\
\hline Length X (m) & 14.742 \\
Length Y (m) & 30.232 \\
Length Z (m) & 11.398 \\
Volume $\left(\mathrm{m}^{3}\right)$ & 5072.3 \\
Centroid X (m) & 2.03 \\
Centroid Y (m) & 5.1211 \\
Centroid Z (m) & 4.339 \\
Nodes & $1,416,719$ \\
Elements & $8,269,091$ \\
\hline
\end{tabular}

The location of boundary conditions is defined both in the area around the object and the flow to determine the grid's size (mesh). Based on the grid independence test, at sizing 0.2 , the maximum velocity value is $4.97 \mathrm{~m} / \mathrm{s}$. Then the maximum velocity value tends to be constant. Based on this, the value of 0.20 can be chosen as the sizing for future simulations. Before the numerical simulation, domain creation was designed. The domain is in the form of a box with formal boundaries that are adjusted to ITTC provisions. The boundary location in question can be seen in Table 3 and Figure 6 for the computational domain of the applied velocity condition, and free surfaces.

Table 3. Boundary location for computational fluid dynamics.

\begin{tabular}{|c|c|c|c|}
\hline Boundary & Property & Size & Description \\
\hline Inlet (X-axis) & Pressure Inlet & 1-Lpp * from front of the float & Fluid entry from the enclosure $(\mathrm{m} / \mathrm{s})$ \\
\hline Outlet $(X+$ axis $)$ & Pressure Outlet & 2-Lpp * from behind of the float & $\begin{array}{l}\text { Fluid discharge from inside } \\
\text { the enclosure }\end{array}$ \\
\hline Boundary (Y-aixs) & Wall & 1-Lpp * from the side of the float & Area of water for the simulation \\
\hline Symmetry $(\mathrm{Y}+$ axis $)$ & Symmetry & 0.5 from the side of the float & $\begin{array}{l}\text { Symetrical distance of the float with } \\
\text { the boundary area }\end{array}$ \\
\hline Boundary (Z-aixs) & Wall & 1-Lpp * from upper side of the float hull & $\begin{array}{l}\text { The space for the upper side of } \\
\text { the float }\end{array}$ \\
\hline Boundary $(Z+$ axis $)$ & Wall & 3-Lpp * lower side of the float hull & $\begin{array}{l}\text { Conditioning deep water areas } \\
\text { for simulation }\end{array}$ \\
\hline
\end{tabular}

\footnotetext{
${ }^{*}$ Lpp (Length between perpendiculars).
} 


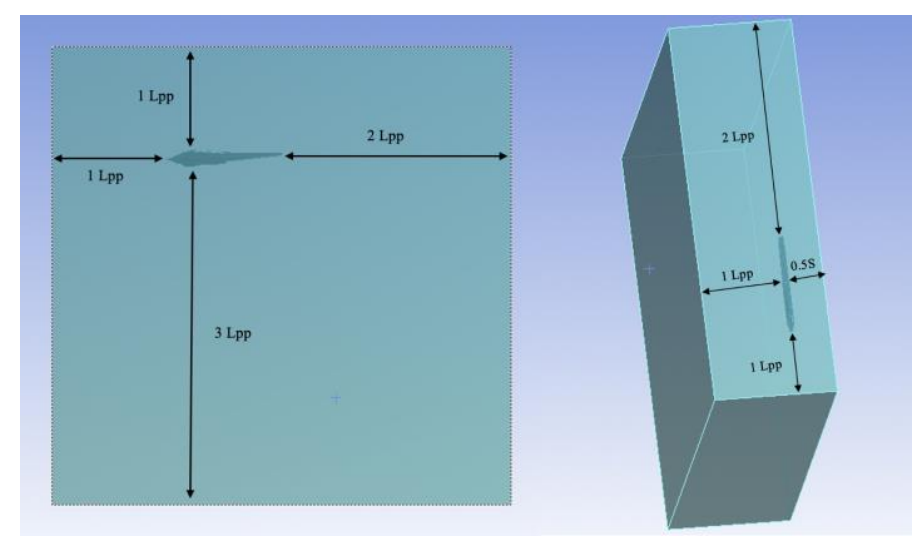

Figure 6. The computational domain of the applied velocity condition, and free surfaces.

\subsubsection{Setup Process}

After the pre-processing stage is carried out, the settings are made in the setup. The numerical test in this study uses a pressure-based solver type with time transient. In the Multiphase Model setting, the Volume of Fluid (VOF) method of the open channel flow sub-model is used with the implicit parameter (Figure 2). The selected flow conditions are turbulent RANS (Reynold Average Navier-Stroke) with the SST k- $\omega$ turbulent model. Based on the specifications determined by [25], the turbulence equation produced by RANS (6) [26] and SST (7) [27] modeling can be seen in the following equation:

$$
\begin{aligned}
& \frac{\partial \omega}{\partial t}+U_{j} \frac{\partial \omega}{\partial x_{j}}=P_{k}-\beta(k \omega)+\frac{\partial}{\partial x_{j}}\left[\left(v+\sigma_{k} \cdot \mathrm{v}_{\mathrm{T}}\right) \frac{\partial k}{\partial x_{j}}\right] \\
& \frac{\partial \omega}{\partial t}+U_{j} \frac{\partial \omega}{\partial x_{j}}=\alpha S^{2}-\beta\left(\omega^{2}\right)+\frac{\partial}{\partial x_{j}}\left[\left(v+\sigma_{\omega} \cdot \mathrm{v}_{\mathrm{T}}\right) \frac{\partial \omega}{\partial x_{j}}\right]
\end{aligned}
$$

The multiphase model and viscous model, the phase selection for simulation is carried out. Since the simulation conditions are between water fluid and air-fluid, two phases were chosen in the simulation, namely phase 1 for air-fluid and phase 2 for water-liquid fluid with seawater properties using the attended Froude number (Fn) is 0.4 to 0.7 with a 0.05 interval.

\subsubsection{Solving Process}

The CFD solvers will calculate the previously applied conditions to the pre-processing and setup processes at this stage. Before starting the simulation test, the run calculation is set by selecting a timescale factor of 0.5 with several iterations of 500 . Parameters used in ANSYS simulation; the pressure is $101,325 \mathrm{~Pa}$, the viscosity is $1.09 \times 10^{-3}$, the density is $1025 \mathrm{~kg} \cdot \mathrm{m}^{-3}$, and the type of fluid that flows is seawater flow described in the previous section with turbulent flow properties. Finally, the data obtained is calculated based on the viscosity resistance $\left(R_{v}\right)$, frictional resistance $\left(R_{F}\right)$, wave resistance $\left(R_{w}\right)$, and air resistance $\left(R_{A A}\right)$ to total all the performing resistance $\left(R_{T}\right)$ for numerical simulations [13].

$$
\begin{gathered}
R_{T}=R_{V}+R_{F}+R_{W}+R_{A A} \\
R_{F}=511.8\left(S V^{2} C_{F}\right) \\
R_{W}=0.25\left[\rho g a^{2}\left(\frac{\sin 2 k H-k H}{\sin 2 k H}\right)\right] ; k=2 \frac{\pi}{\lambda} \\
R_{A A}=0.5\left(C_{A} \mathrm{~A}_{T} V^{2} \rho\right) \\
R_{V}=C_{F}+19\left(\frac{\nabla}{L w l^{2} \cdot T}\right)^{2} \cdot C_{F}
\end{gathered}
$$




$$
C_{F}=0.075\left[\left(\log _{10} R_{n}\right)-2\right]^{-2}
$$

Note: $S=$ wetted surface, $V=$ float speed, $H=$ float height,$k=$ Constant,$a=$ acceleration, $C_{A}=$ air coefficient, $C_{F}=$ frictional coefficient, $R_{n}=$ Reynolds number, $L w l=$ length waterline, $B=$ Breadth, $T=$ Draft, $\lambda=$ wavelength.

\section{Results and Discussion}

Before discussing the numerical test results, things need to be considered about the flow of discussion in the study by looking at the facts resulting from the resulting calculations. Secondly, what causes these results, the causal flow of the calculations and numerical simulations can be known. The design validation flow carried out; a comparison based on a predetermined design is needed to adapt a float design with biomimicry to the Wipe line ${ }^{\circledR} 13000$ design as a conventional design.

Subsequent comparisons are made to several similar methods, namely adaptation to other fish species and drag reduction methods for hull or float. The float design is optimized using other parameters such as trim variations, deadrise angle variations, and clearance distance variations to get the optimum biomimicry adaptation float configuration.

\subsection{Design Comparison Analysis}

Based on the data obtained from the numerical test results of control designs 1 to 3 , it was found that the highest resistance value was in control design I with a value of $11,603.00$ Newton with a Froude number of 0.40 and a maximum value of 24,267.00 Newton at a Froude number of 0.70 . This figure decreased when the control II design was used. The resistance value is reduced to 623.11 Newton at Froude number 0.40, and at Froude number 0.70 , this number reaches 1396.92 Newton. This value is considered drastic because the decrease is due to the more streamlined design used compared to the Wipe line ${ }^{\circledR} 13000$ design. However, the control II design is not yet the final design, so a test design is needed to have an updated contribution to the old design by adapting the shape of the sailfish. An improvement can be seen based on the form or in terms of numerical test results. The test resistance value is between the control design resistance values 1 and 2 with a minimum value of $2126.54 \mathrm{~N}(\mathrm{Fn}=0.40)$ and a maximum value of $4452.88 \mathrm{~N}(\mathrm{Fn}=0.70)$. The results of the comparison of the three designs can be seen in Figure 7.

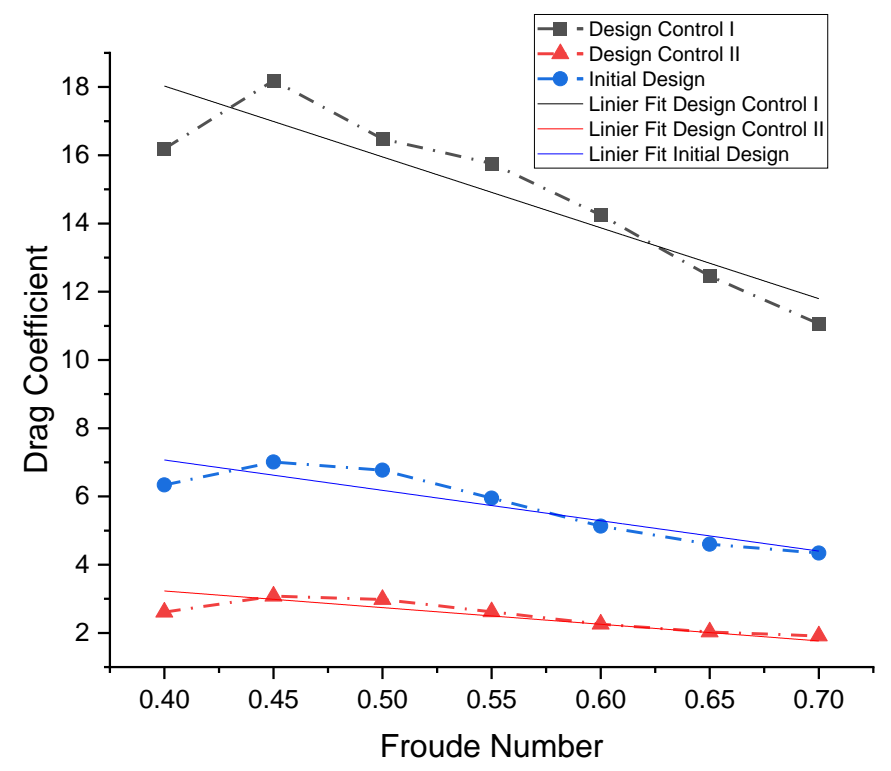

Figure 7. Coefficient drag vs. Froude number of the design model (design control I, design control II, and initial design).

Based on the results shown, the three designs experienced a reduction resistance value and increased the Froude number value. The resulting resistance can be seen in comparison 
with a similar study [28]; the analysis carried out on the hull surface wall of the barge model ship was a $3.89 \%$ reduction. In the study, the reduction occurred by $18.322 \%$ using the bio-mimicry design of the sailfish body. The results show that Yanuar et al. [7] and Zaghi et al. [14] supports the output of this study. The numerical condition is influenced by wave resistance, hydrodynamic resistance, and viscosity, affecting the wave interference factor. When compared with the control II design, the test design has a low resistance value. According to the discussion, another cause of drag is the sailfish body dimension, which reduces resistance significantly compared to Svendsen et al. results [10]. This analysis gives the researcher confidence that biomimicry efforts by adopting the shape of a sailfish on a floating stomach will significantly reduce the resistance value.

\subsection{Trim Variation Analysis}

Analysis to determine the effect of waves, hydrodynamic resistance can be clarified with three other parameters. Trim variations test is carried out with the number of cells and errors following the recommendations used by the ITTC (International Towing Tank Conference) CFD Recommendation 2011 [29]. The tests were carried out with 11 configuration models with variations in trim angle, discussed in the sub-chapter above. The value of the trim variation shows the value of the increase in the stern obtained in Table 4 .

Table 4. Trim variation with different stern rise.

\begin{tabular}{cccc}
\hline Trim Variation $(\boldsymbol{\theta})$ & Stern Rise $(\mathbf{m})$ & Trim Variation $(\boldsymbol{\theta})$ & Stern Rise $(\mathbf{m})$ \\
\hline-2.2 & 0.19 & 0 & 0 \\
-1.76 & 0.152 & 0.44 & -0.038 \\
-1.32 & 0.114 & 0.88 & -0.076 \\
-0.88 & 0.076 & 1.32 & -0.114 \\
-0.44 & 0.038 & 1.76 & -0.152 \\
0 & 0 & 2.2 & -0.19 \\
\hline
\end{tabular}

This negative trim value is also known as trim by stern. Then the negative trim value of 2.2 degrees produces $0.19 \mathrm{~m}$ with the stern down position. Meanwhile, for positive trim values, it is also called trim by the head. Then a positive trim value of 2.2 degrees produces $0.19 \mathrm{~m}$ with a bow or head down position. From the numerical processing of data using ANSYS Fluent software above, the Froude Number graph is obtained as the (x) axis and the total resistance value in Newtons on the (y) axis. The following is a graph on the trim by bow and trim by stern configuration. Based on Figure 8, the trendline is the total resistance value $\left(R_{T}\right)$. In the trim by bow graph, the total resistance value $\left(R_{T}\right)$ increases with the increase in Fn for all trim values. The total resistance value in trim by bow experienced a significant increase compared to the total resistance value $\left(R_{T}\right)$ in trim by stern and even keel. The lowest average total resistance $\left(R_{T}\right)$ is found in the trim value of 0.038 trim by the bow of $1,674,341 \mathrm{~N}$. 


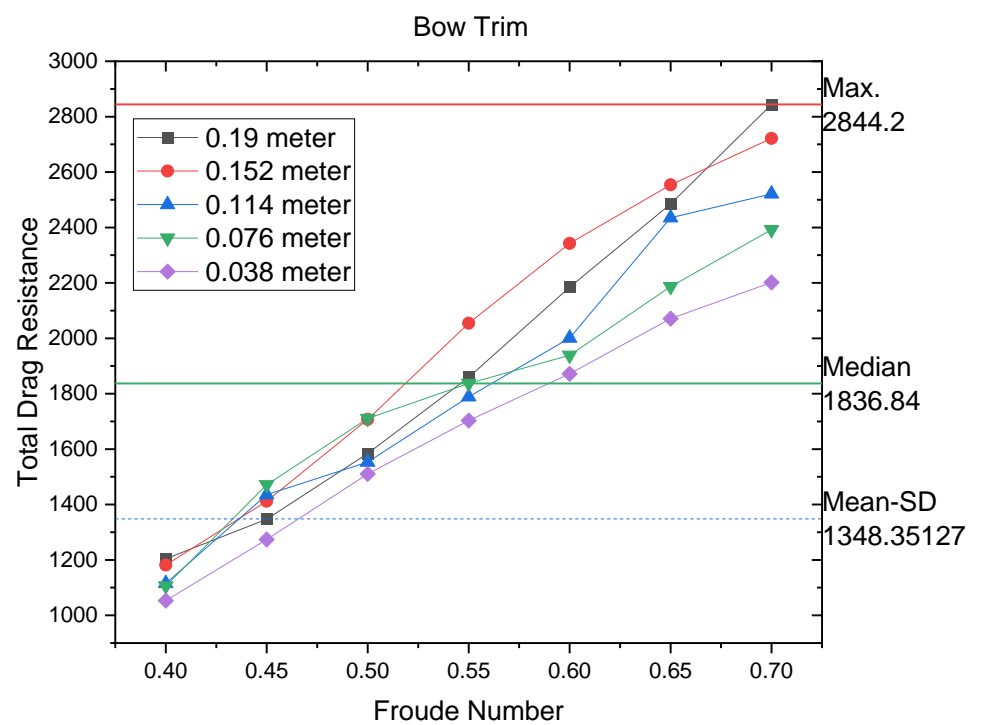

(a)

Stern Trim

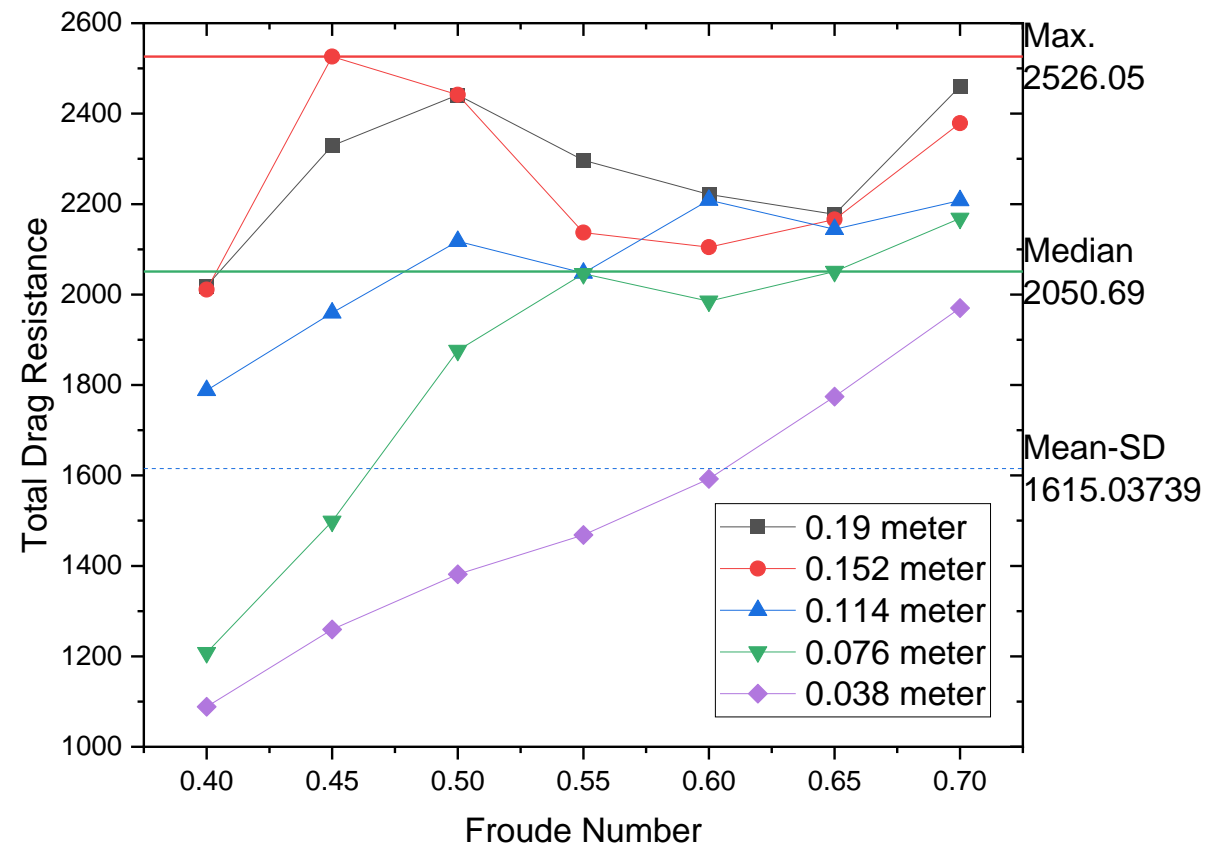

(b)

Figure 8. Total drag vs. Froude number of the trim variation on the initial design for bow trim (a) and stern trim $(\mathbf{b})$.

Then, it can be seen in the graph that the trim by stern value for the total resistance value $(R t)$ continues to increase at the even keel and trim of $0.038 \mathrm{~m}$. However, at the trim value of $0.076 \mathrm{~m}$ at Fn $0.6, R_{T}$ decreased by $62.5 \mathrm{~N}$ before rising again to Fn 0.7 . The same thing happens in the next trim, where a certain Fn will experience a decrease before increasing again to Fn 0.7. According to Fenster et al. [12], it occurs due to changes in the value of wave and viscosity resistance by increasing the trim and ship speed. The lowest average total resistance value $\left(R_{T}\right)$ is found in the trim value of $0.038 \mathrm{~m}$ trim by the stern of 1500.004 N.

The lowest average resistance occurs from the results obtained when the hull moves in the Fn 0.4 condition. The following is the relationship between the total resistance value $\left(R_{T}\right)$ and the trim value in the Fn 0.4 condition for further analysis. Trim value of $0.038 \mathrm{~m}$ 
positive by stern is the lowest point for the total resistance value $\left(R_{T}\right)$ obtained before the value rises again for a more considerable trim value. The effect is this occurs due to changes in the value of wave resistance and viscosity resistances at each increase in trim and ship speed. As shown in the graph on the right, the optimal trim obtained is $0.02 \mathrm{~m}$ positive by the stern. It turns out that the trim value of $0.038 \mathrm{~m}$ positive by stern is the most optimal trim overall because the trim value produces the lowest average total resistance value for all Fn ( 0.2 to 0.7 with an interval of 0.05$)$ with a difference of $15.33 \%$ of the total resistance value at the time of even keel. So, the most appropriate trim value for the float adaptation design is $0.38 \mathrm{~m}$ stern trim.

\subsection{Deadrise Angle Variation Analysis}

After looking at the analysis based on trim variations, the initial design's optimization effect using deadrise angle variations is also seen in Figure 9. In the resistance graph above, the conventional design has a much larger resistance value with the new design adapting the fish body to a deadrise angle of $20^{\circ}$. The increase in resistance also looks more significant in conventional barriers in the Froude number range from 0.7 to 0.9 . This could be due to the slimmer body shape of the sailfish compared to conventional designs. When the float travels at high speed, of course, the slim body shape of the float tends to produce less resistance. The significant increase in drag on the sailfish body design looks more stable than the conventional design. At high speed, namely at Froude number 0.9, the difference in resistance between the two designs is $\mathrm{R}_{\mathrm{T}}=4.644 \mathrm{kN}$.

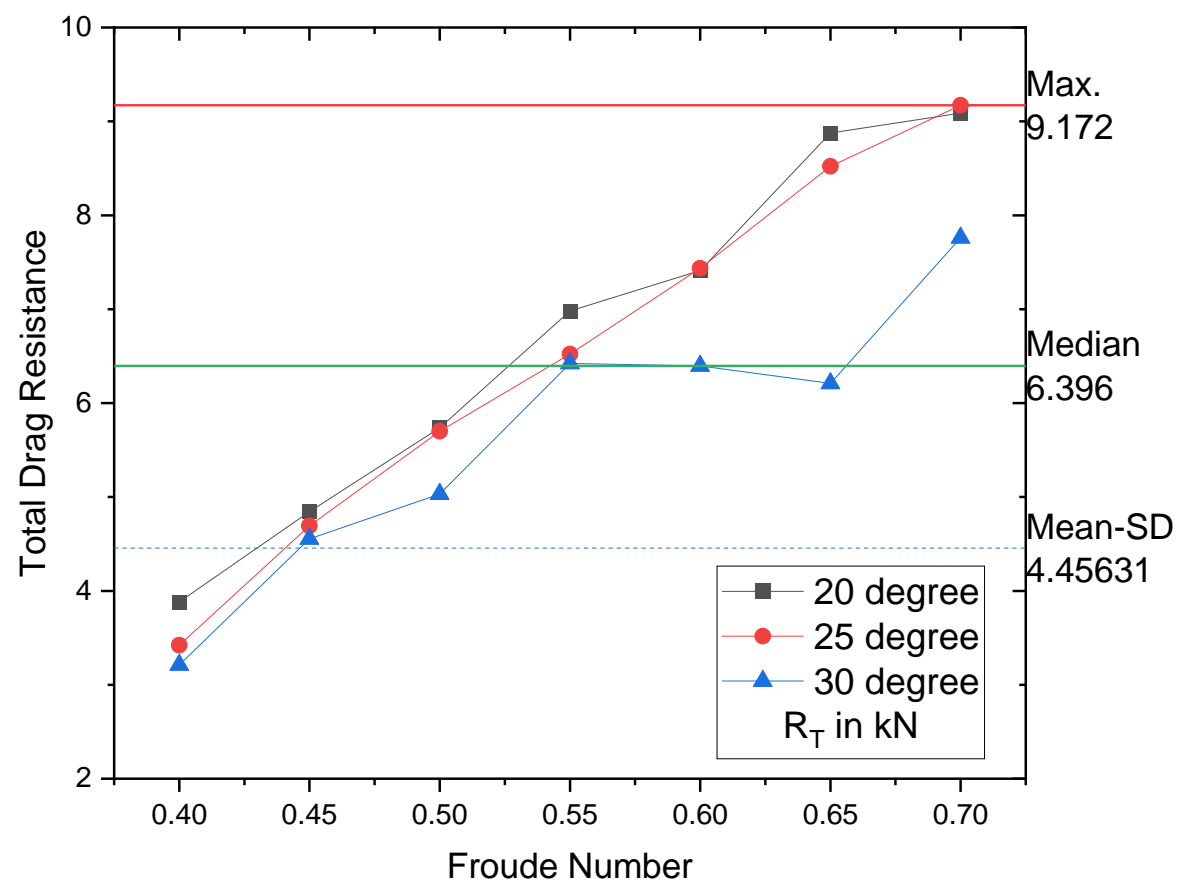

Figure 9. Total drag vs. deadrise angle variation of the initial design compared to Wipeline ${ }^{\circledR}$ 13000 design.

Meanwhile, the $25^{\circ}$ deadrise angle variation resistance is not much different from the $20^{\circ}$ deadrise angle variation, and the increase in resistance tends to be stable. In the Froude number range $0.7-0.9$, both models significantly differ in total resistance compared to conventional designs, which have a more considerable resistance value. The resistance ratio from the graph above shows a relatively significant difference in resistance. The $30^{\circ}$ deadrise angle design seems to have a much smaller resistance than the conventional design. The increase in resistance at the $30^{\circ}$ deadrise angle also looks stable. It can be seen that the design of the fish body with a $30^{\circ}$ deadrise angle has a much smaller resistance 
compared to the conventional design at high speed, namely, the Froude number 0.9 has a difference in resistance of $\mathrm{R}_{\mathrm{T}}=6.448 \mathrm{kN}$.

The $30^{\circ}$ deadrise angle biomimicry design has the highest $R_{T}$ value compared to the $20^{\circ}$ and $25^{\circ}$ deadrise designs. Based on the graph above, the biomimicry design with variations in deadrise angles of $20^{\circ}, 25^{\circ}$, and $30^{\circ}$ has a total resistance far below the conventional design's total resistance. It can also be seen that the higher the speed, the more desirable the resistance will also increase. Biomimicry with a $30^{\circ}$ deadrise angle has the best performance because of the smallest resistance value. The total resistance coefficient seen in the graph shows that the total resistance coefficient $30^{\circ}$ is the smallest. While the variations of $20^{\circ}$ and $25^{\circ}$ have almost similar characters, the Froude number 0.5 to 0.7 , the variation of $25^{\circ}$ has a smaller resistance coefficient value compared to the variation of $20^{\circ}$. However, when the Froude number ranges from 0.7 to 0.9 , the $20^{\circ}$ has more resistance coefficient value. From the graph, the variation of $30^{\circ}$ has good performance because it has a slight drag coefficient. In Figure 10, you can see the simulation results of the design performance with a different deadrise angle configuration with Froude number 0.6.

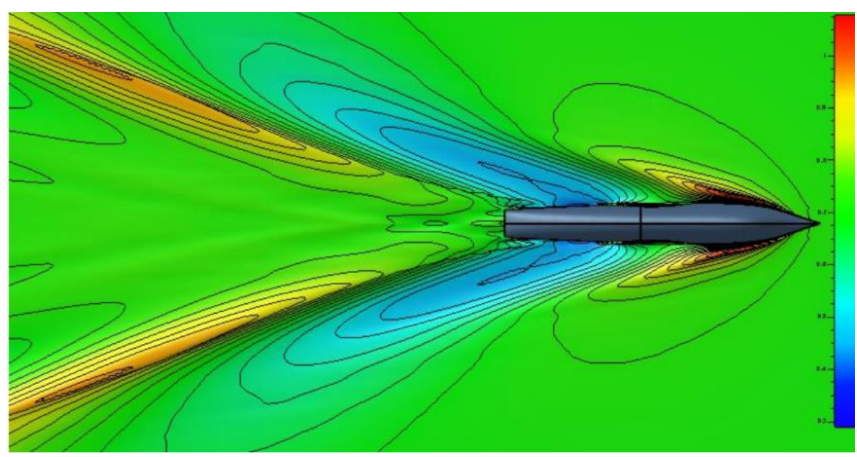

(a)

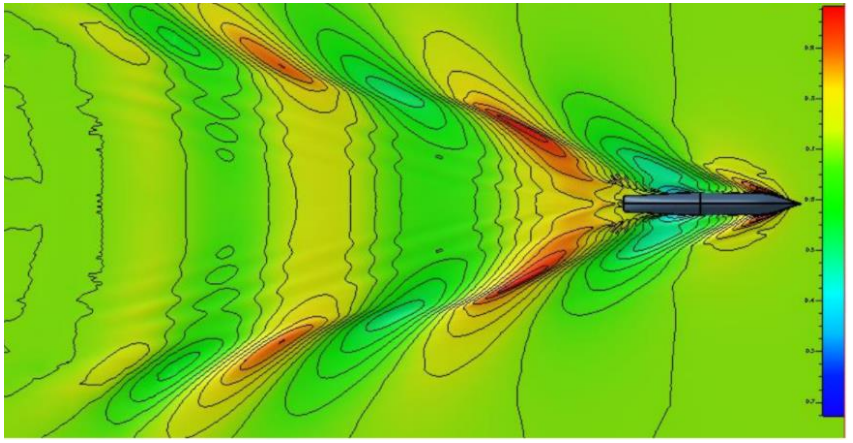

(b)

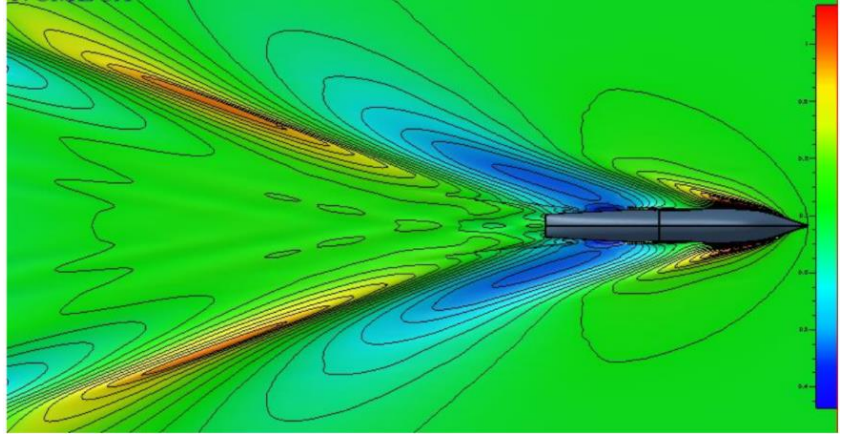

(c)

Figure 10. Different deadrise angle configuration with Froude number 0.6 ; (a) $20^{\circ}$; (b) $25^{\circ}$; (c) $35^{\circ}$. 


\subsection{Interference Factor Analysis}

Final thing to be considered is the clearance factor of both floats. A seaplane consists of two floats that helps it to perform landing on top of surface of the sea, Indonesia N219 seaplane in particular uses two floats, therefore it is clear to perform analysis of interference factor. Figure 11 shows the interference factor to be an exceptional influence on the ship's resistance. This factor occurs due to the meeting of two waves that arise due to the moving multihull. The interference factor has two possible outcomes, namely negative and positive values. The negative interference factor produces destructive interference waves, which attenuate each other so that the total resistance generated by the waves is reduced and is favorable to the catamaran's hull. On the other hand, the positive interference factor produces constructive interference, which causes the two waves produced to produce amplitudes between waves that are mutually reinforcing so that the wave resistance increases.

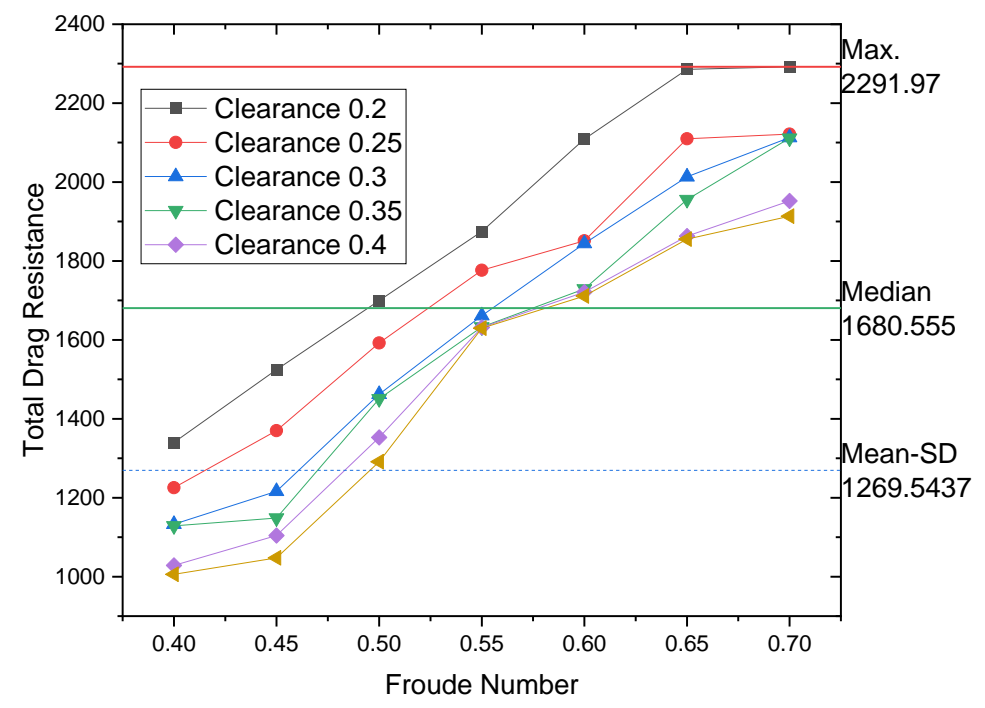

Figure 11. Total drag vs. Froude number by clearance factor.

The graph above shows that each clearance has increased the interference value until it reaches the maximum value at Froude Number 0.5. Furthermore, the wave interference value began to decrease until it touched the Froude Number 0.7. The value of the interference factor also decreases as the value of the clearance variation increases. This design also has negative interference values in several clearance configurations, namely clearance $0.35-0.45$ on Froude Numbers 0.4 and 0.7 and clearance 0.25 on Froude Number 0.7 with a clearance of 0.45 on Froude Number 0.4 smallest interference factor value. The findings show optimal conditions for this catamaran's hull design to obtain favorable destructive interference for the hull resistance, namely at 0.45 clearance in Froude Number 0.7. Similar results were obtained by Sulistyawati et al. [30], where the wave interference value increased until it reached the maximum value in the Froude Number 0.5 and subsequently decreased the wave interference value. The decrease in the value of wave interference also occurs as the distance between the hulls increases. The effect on wave interference can be seen in Figure 12 which shows wave interference at different Froude numbers.

Based on the results, a common thread can be drawn from the analysis carried out in the previous discussion. The initial design was used as a replacement design for the Wipeline ${ }^{\circledR} 13000$. The initial design can produce a design with much less resistance than the Wipeline ${ }^{\circledR} 13000$ design that there is an $18 \%$ reduction in drag. However, the efficiency can be increased with more configurations such as trim degree configuration, deadrise angle, and interference factor. The critical points from these results can be seen in the conclusion section below. 


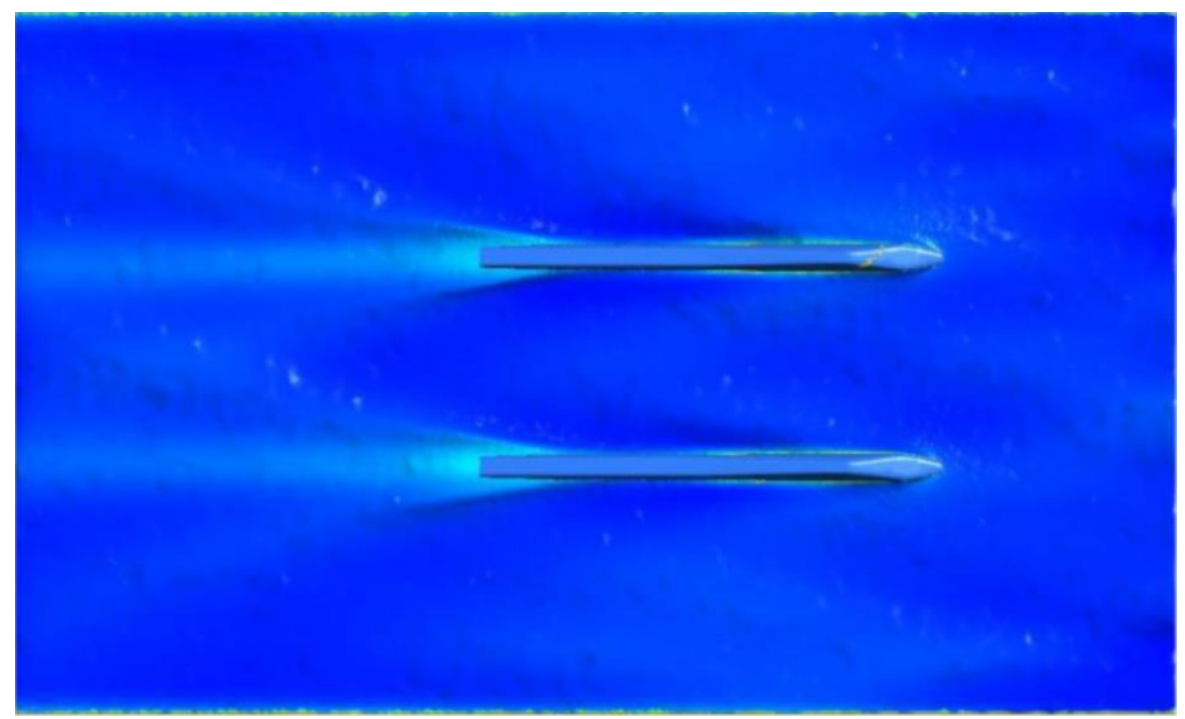

(a)

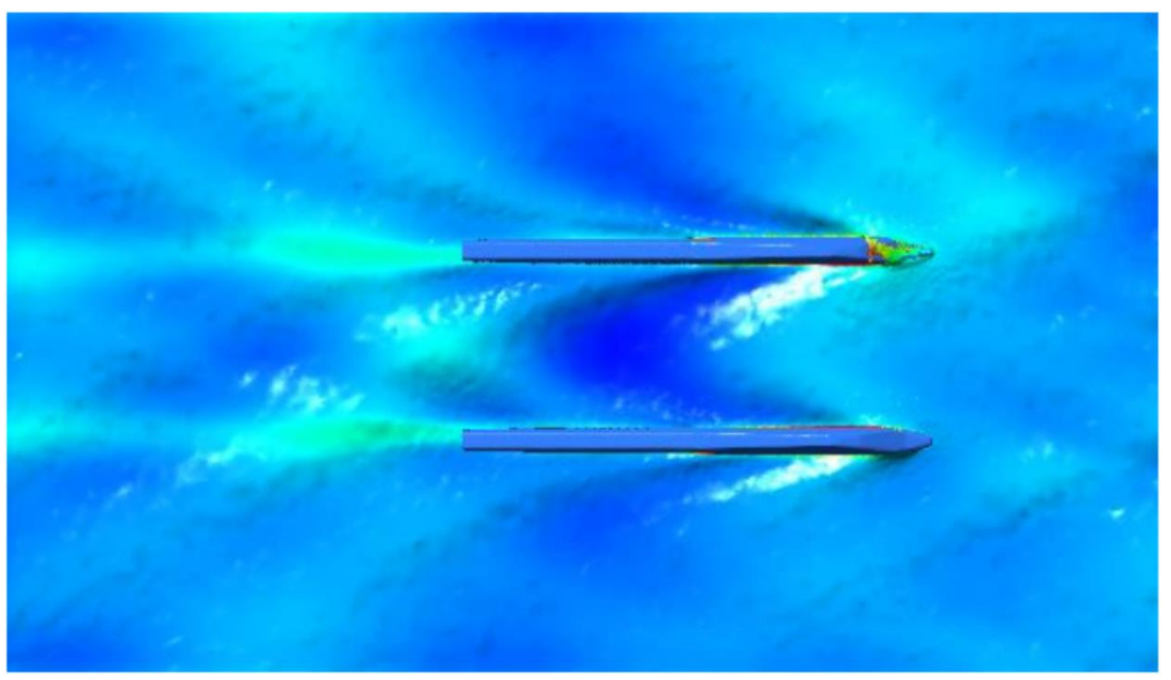

(b)

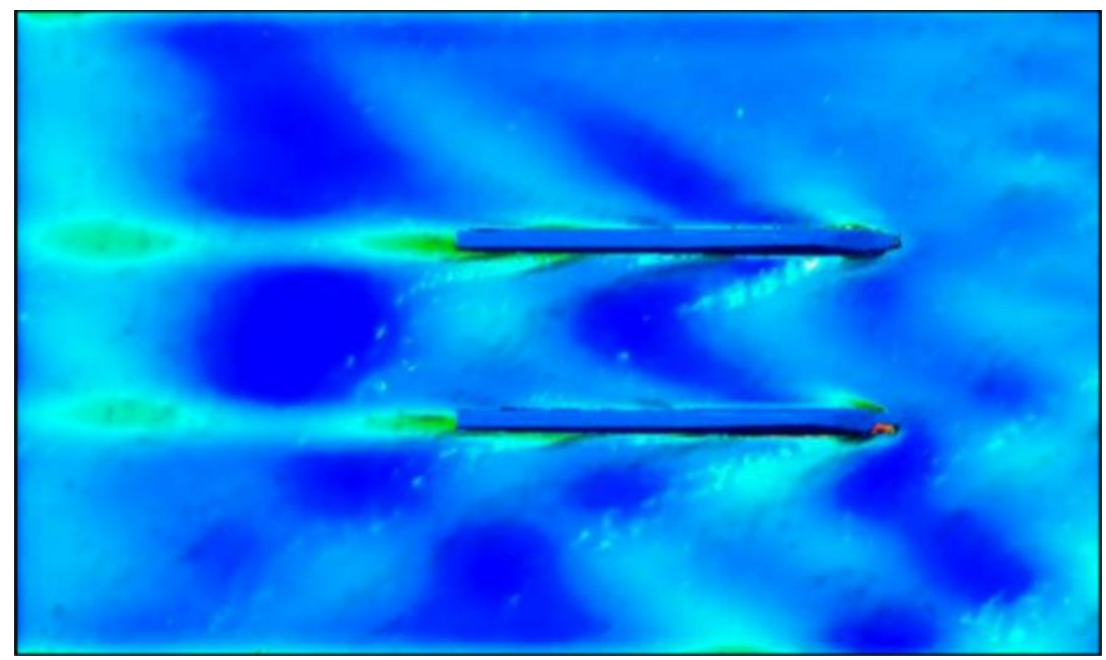

(c)

Figure 12. Wave interference at different Froude numbers: (a) 0.45 ; (b) 0.55 ; (c) 0.65 . 


\section{Conclusions}

Based on the research results that have been discussed, the conclusion drawn from this investigation is that there is a significant difference between the float design resistance value of Wipeline ${ }^{\circledR} 13000$ and the biomimicry adaptation design. The adaptation design uses the hydrodynamic characteristics of the body sailfish to lower the drag on the Indonesian N219 seaplane catamaran float. It is supported with analysis that shows a reduction in resistance of $18.32 \%$ by using the sailfish design as a reference for floating floats. Second, with the trim analysis using a numerical test of float configuration with the smallest average total resistance value $\left(R_{T}\right)$, the trim by stern variation is $0.038 \mathrm{~m}$ in all Froude Numbers. Meanwhile, the most significant total resistance value $\left(R_{T}\right)$ occurs in the trim by bow variation of $0.19 \mathrm{~m}$ with Froude Number (Fn) 0.70 with a value of $2844.2 \mathrm{~N}$. The lowest point for the resistance value is $1053.4 \mathrm{~N}$ when driving with Fn 0.4.

Third, from all variations of biomimicry designs, designs with deadrise angle $=30^{\circ}$ 73 Universitas Indonesia which has the best performance in reducing resistance than the other two designs. Thus, the modification of the biomimicry design with an increase in deadrise angle variation is not linearly proportional to the reduction in resistance. Finally, the clearance value $(\mathrm{S} / \mathrm{L})$ can also reduce the drag coefficient produced by the catamaran float and vice versa. Reducing the clearance value increases the resistance coefficient value produced by the catamaran float. The design has a negative interference factor (IF) value in several conditions, indicating that the design has optimal conditions to reduce the resistance generated by the catamaran hull.

Author Contributions: Conceptualization, Y. and A.U.; methodology, A.U.; software, A.U.; validation, A.U., G. and Y.; formal analysis, A.U.; investigation, A.U.; resources, G.; data curation, A.U.; writing—original draft preparation, A.U.; writing—review and editing, A.U. and G.; visualization, A.U.; supervision, Y.; project administration, G.; funding acquisition, Y. All authors have read and agreed to the published version of the manuscript.

Funding: This research was funded by the Ministry of Research and Technology/National Research and Innovation Agency of Indonesia, grant number NKB -040/UN2.RST/HKP.05.00/2021.

Data Availability Statement: Data is available at https: / / drive.google.com/drive/folders/1aXENi2 Vh7gRADOi87LxXhZb0kkIlBvpw?usp=sharing, accessed on 5 November 2021.

Acknowledgments: The author would like to thank Fadlu Rahman Sirajudin Majid, Muthia Aurora Balqis Baezal, Zahwa Chairunisa, and Antoni in providing the data of the initial design of N219 seaplane design the following work would not be possible without their hard work and consistency.

Conflicts of Interest: The authors declare no conflict of interest The funders had no role in the design of the study; in the collection, analyses, or interpretation of data; in the writing of the manuscript, or in the decision to publish the results.

\section{References}

1. The Science of Flight: Aeroplanes, Seaplanes and Aero Engines. Nature 1929, 124, 8. [CrossRef]

2. Seaplane, S. And Float/Ski Equipped Helicopter Operations Handbook. Fed. Aviat. Adm. 2004, 2, 20.

3. Gudmunsson, S. Appendix C3: Design of Seaplanes; Elsevier Inc.: Oxford, UK, 2013.

4. Yanuar, Y.; Gunawan, G.; Utomo, A.; Luthfi, M.; Baezal, M.; Majid, F.; Chairunisa, Z. Numerical and Experimental Analysis of Total Hull Resistance on Floating Catamaran Pontoon for N219 Seaplanes Based on Biomimetics Design With Clearance Configuration. Int. J. Technol. 2020, 11, 1397. [CrossRef]

5. Yongxing, Z.; Kim, D. Optimization Approach for A Catamaran Hull Using CAESES and STAR-CCM+. J. Ocean Eng. Technol. 2020, 34, 272-276. [CrossRef]

6. Milward, A. The Effect of Hull Separation and Restricted Water Depth on Catamaran Resistance. Trans. R. Inst. Nav. Archit. 1992, 134, 341-349.

7. Ibadurrahman, I.; Gunawan, A.; Wibowo, R.A. Drag Reduction Of X-Pentamaran Ship Model with Asymmetric-Hull Outrigger Configurations and Hull Separation. Energy Rep. 2020, 6, 784-789.

8. Carry, J.; Crouse, G. Preliminary Design Optimization of an Amphibious Aircraft. Master's Thesis, Auburn University, Auburn, AL, USA, 2012.

9. Ramírez-Pérez, J.; Quiñonez-Velázquez, C.; Abitia-Cardenas, L.; Melo-Barrera, F. Age and Growth of Sailfish Istiophorus Platypterus (Shaw in Shaw and Nodder, 1792) From Mazatlan, Sinaloa, Mexico. Environ. Biol. Fishes 2011, 92, 187-196. [CrossRef] 
10. Svendsen, M.; Domenici, P.; Marras, S.; Krause, J.; Boswell, K.; Rodriguez-Pinto, I.; Wilson, A.; Kurvers, R.; Viblanc, P.; Finger, J.; et al. Maximum Swimming Speeds of Sailfish and Three Other Large Marine Predatory Fish Species Based on Muscle Contraction Time and Stride Length: A Myth Revisited. Biol. Open 2016, 5, 1415-1419. [CrossRef] [PubMed]

11. Sagong, W.; Jeon, W.; Choi, H. Hydrodynamic Characteristics of The Sailfish (Istiophorus Platypterus) And Swordfish (Xiphias Gladius) In Gliding Postures at Their Cruise Speeds. PLoS ONE 2013, 8, e81323. [CrossRef]

12. Fenster, B.J.; Fenster, A.L. Guide to Seaplane Flying. 2019. Available online: https://www.amazon.com/Guide-Seaplane-FlyingBradley-Fenster/dp/1686219792 (accessed on 5 November 2021).

13. Jamaluddin, A.; Utama, I.; Molland, A. Experimental Investigation into The Drag Characteristics of Symmetrical and Asymmetrical Staggered and Unstaggered Catamaran. In Proceedings of the International Conference on Ship \& Offshore Technology (ICSOT)-Indonesia, Surabaya, Indonesia, 11-12 November 2010.

14. Zaghi, S.; Broglia, R.; Di Mascio, A. Analysis of The Interference Effects for High-Speed Catamarans by Model Tests and Numerical Simulations. Ocean Eng. 2011, 38, 2110-2122. [CrossRef]

15. Lyu, X.; Tu, H.; Xie, D.; Sun, J. On Resistance Reduction of A Hull by Trim Optimization. Brodogradnja 2017, 69, 1-13. [CrossRef]

16. Kim, J.; Oh, W.; Hong, C.; Kim, D. A Study on The Trim and Resistance of Small Catamaran Using Numerical Analysis and A Model Test. J. Korean Soc. Mar. Environ. Saf. 2018, 24, 591-596. [CrossRef]

17. Hajiabadi, A.; Shafaghat, R.; Kazemi Moghadam, H. A Study into The Effect of Loading Conditions on The Resistance of Asymmetric High-Speed Catamaran Based on Experimental Tests. Alex. Eng. J. 2018, 57, 1713-1720. [CrossRef]

18. Sherbaz, S.; Duan, W. Ship Trim Optimization: Assessment of Influence of Trim on Resistance of MOERI Container Ship. Sci. World J. 2014, 2014, 603695. [CrossRef] [PubMed]

19. Davis, B.W. Analysis of Results—Hydrodynamic Research Project; Boeing Aircraft Company: New York, NY, USA, 1944.

20. Craftsmen At Boeing Aircraft. Design 1944, 45, 4-5. [CrossRef]

21. Souto-Iglesias, A.; Fernández-Gutiérrez, D.; Pérez-Rojas, L. Experimental Assessment of Interference Resistance for A Series 60 Catamaran in Free and Fixed Trim-Sinkage Conditions. Ocean Eng. 2012, 53, 38-47. [CrossRef]

22. Everest, J. Some Research on the Hydrodynamics of Catamarans and Multi-Hulled Vessels in Calm Water. Northeast Coast Institution of Engineers and Shipbuilders, 1968; pp. 1-20. Available online: https:/ / repository.tudelft.nl/islandora/object/uuid: 0c12ba98-2648-4ebd-80f7-50c3834ab40d?collection=research (accessed on 5 November 2021).

23. Zhang, B.; Zhang, C.; She, W. The Minimum Wave Resistance of Hull Form Design Method Based on CFD Method. J. Ship Prod. Des. 2020, 36, 161-170. [CrossRef]

24. Oving, A. Resistance Prediction Method for Semi Planing Catamarans with Symmetrical Demi-Hulls. Master's Thesis, Graduate Program. Delft University of Technology, Mekelweg, The Netherlands, 1985.

25. Shiotani, S.; Kodama, Y. Numerical Analysis on Free Surface Waves and Stern Viscous Flow of a Ship Model. J. Mar. Sci. Technol. 1998, 3, 130-144. [CrossRef]

26. Alfonsi, G. Reynolds-Averaged Navier-Stokes Equations for Turbulence Modeling. Appl. Mech. Rev. 2009, 62, 040802. [CrossRef]

27. Menter, F.; Kuntz, M.; Langtry, R. Ten Years of Industrial Experience with The SST Turbulence Model. Turbul. Heat Mass Transf. 2003, 4, 625-632.

28. Ibrahim, M.; Amran, S.; Yunos, Y.; Rahman, M.; Mohtar, M.; Wong, L.; Zulkharnain, A. The Study of Drag Reduction on Ships Inspired by Simplified Shark Skin Imitation. Appl. Bionics Biomech. 2018, 2018, 7854321. [CrossRef] [PubMed]

29. ITTC Procedure. Recommended Procedures and Guidelines. Practical Guidelines for Ship CFD; Application 7.5-03-01-01; ITTC Procedure: Lawrence, KS, USA, 2011; pp. 11-18.

30. Sulistyawati, W.; Pamitran, A. The Influences of Diversity Hull Shapes and Outriggers Arrangement in Pentamaran Systems. Energy Rep. 2020, 6, 595-600. [CrossRef] 